Orthopäde 2015 - 44:211

DOI 10.1007/s00132-014-3074-8

Online publiziert: 5. März 2015

(c) Springer-Verlag Berlin Heidelberg 2015

D. Niederer · J. Wilke · E. Füzéki · W. Banzer

Abteilung Sportmedizin, Goethe-Universität Frankfurt, Frankfurt a. M., Deutschland

\title{
Erratum zu: Sportliche Belastungen nach Spondylodesen der Lendenwirbelsäule
}

\section{Der Return-to-play-Prozess}

Leider wurde das elektronische Ergänzungsmaterial zu diesem Beitrag nicht vollständig dargestellt. Die vollständigen Kasuistiken zur sportlichen Belastung nach Spondylodesen finden Sie jetzt unter doi:10.1007/s00132-014-3074-8.

Wir bitten diesen Fehler zu entschuldigen.

Die Redaktion

\section{Zusatzmaterial online \\ Die Online-Version dieses Artikels (doi: 10.1007/s00132-014-3074-8) enthält zusätzli- ches Material, welches für autorisierte Benut- zer zugänglich ist.}

\section{Korrespondenzadresse}

Dr. D. Niederer

Abteilung Sportmedizin

Goethe-Universität Frankfurt,

Ginnheimer Landstraße 39

60487 Frankfurt a. M.

niederer@sport.uni-frankfurt.de 